\title{
A DOCENTE DE ENFERMAGEM COMO MODELO A SER IMITADO
}

Amália C. de Carvalho *

Pode parecer estranho que ainda se dedique tempo a um assunto considerado ponto pacífico pela maioria dos educadores. Talvez cause mesmo estranheza embora a repetição esporádica contribua para a descoberta de aspectos novos em qualquer tema, por mais explorado que esteja: por isso, a repetição é preconizada e considerada necessária pela metodologia do ensino.

A idéia de abordar o assunto, porém, surgiu da leitura e traclução de oportuno artigo da educadora norte-americana Marlene Kramer, que apresenta a "modelação" como uma estratégia de ensino muito positiva, que facilita e apressa a aprendizagem. Ao enfatizar o valor do "modelo" ou exemplo no ensino, a autora estranha que, aquilo que poderia tornar-se uma técnica valiosa no preparo do pessoal de enfermagem, não esteja merecendo a atenção devida por parte de programas e das docentes das respectivas escolas.

Após descrever uma experiência em que o ensino de campo consistiu em utilizar a docente como enfermeira-modelo, responsável pela assistência direta a pacientes da unidade onde os estudantes estagiavam, com o intuito de ensinar pelo exemplo e provocar comportamentos imitativos, positivos a autora termina afirmando que houve consenso geral entre docentes, enfermeiras do campo e estudantes, sobre a validade do método empregado; afirma que "os estudantes de hoje devem ser orientados por docentes que possam demonstrar como prestar boa assistência de enfermagem..." devem ter oportunidade de imitar esses modelos..."

O objetivo deste trabalho, entretanto, não é advogar a volta das docentes à prática da enfermagem de cabeceira para que possam ensinar pelo exemplo; tão pouco sugerir que o ensino de campo seja

* Docente da Escola de Enfermagem da USP. 
feito pelas enfermeiras dos serviços onde os estudantes estagiam, mesmo que estas constituam modelos dignos de imitação. Os múltiplos problemas que o ensino e o exercício da enfermagem devem enfrentar em nosso meio desaconselham, no momento, qualquer especulação sobre a 'posşibilidade da dupla função, quer seja por parte das docentes, quer seja por parte das enfermeiras do campo. Mudanças profundas na organização dos serviços assistenciais e dos programas das escolas seriam essenciais como ponto de partida para inovaçōes nesse sentido. De qualquer maneira, essas reformas poderiam não alterar as condiçōes atuais em que a enfermeira muito raramente tem tempo para a assistência direta aos pacientes; suas responsabilidades administrativas poderiam torná-la uma administradora-modelo, nem sempre, porém, uma enfermeira-modelo.

O que se pretende é, partindo de uma experiência em que a estratégia de ensino pela "modelação" foi utilizada com êxito, apresentar aspectos do processo ensino-orientação de estudantes de enfermagem em que o papel da docente como modelo a ser imitado deve ser enfatizado, não apenas no que se relaciona à sua competência profissional, mas principalmente em relação às suas atitudes e aos seus valores morais e sócio-profissionais.

Não será, portanto, focalizado o papel da docente ou das profissionais do campo como enfermeiras-modelo na área da assistência direta ou indireta aos pacientes. $\mathrm{O}$ artigo de Marlene Kremer é suficiente elucidativo quanto ao tipo de enfermeiras que podem ser encontradas nos serviços que servem de campo clínico para os estudantes; é ela quem diz: “... havíamos observado que a apatia generalizada entre as enfermeiras do serviço, a falta, no campo de estágio, de bons modelos que demonstrassem gosto e entusiasmo pela enfermagem, e a falta de modelos que desempenhassem tanto o papel expressivo quanto o instrumental da enfermaria, tudo isso colaborava para o atrazo do processo de aprendizagem social da estudante". E possível que essa afirmação seja verdadeira também para o nosso meio e o assunto poderá vir a ser discutido em outra oportunidade.

O que interessa no momento é o aspecto do desenvolvimento das chamadas atitudes profissionais nos estudantes de enfermagem; é a preservação dos valores essenciais de uma profissão tradicionalmente voltada para o bem comum, cujo exercício baseia-se no amor ao próximo, na caridade ou sensibilidade pelos problemas dos pacientes no interesse e na compreensão do ser humano; é a preservação da imagem que o público faz da enfermeira, em seus aspectos pasitivos de profissional competente, humana, compreensiva, discreta, digna de confiança; de pessoa de aparência suave, imaculadamente limpa e bem vestida, sempre presente nas horas de crise e sofrimentos, sempre pronta a servir e consolar. 
As transformaçōes que se fazem sentir em todos os ramos da atividade humana vêm produzindo mudanças no comportamento do homem moderno; os profissinais da área da saúde estão, como os demais, sofrendo a influência do progresso da tecnologia e da modernização dos costumes. A devoção à ciência e à eficiência no trabalho tem levado muitos ao esquecimento dos valores do homem como homem. Como bem disse alguém, referindo-se à prática da medicina, a competência profissional vem em primeiro lugar, mas não há razão para não vir acompanhada de compreensão e simpatia. Essa afirmação poderia ser completada, no caso das enfermeiras: não há razão para não vir acompanhada, também, daquelas qualidades que tornam mulheres mais femininas e mais humanas: sensibilidade, cordialidade, elegância no falar e no vestir, para citar apenas as mais importantes.

A preservação dos prinicípios cristãos de amor e dedicação aos que scfrem, simpatia para com os infelizes e de tolerância para com todcs, sãos e doentes, deve constituir um dos objetivos de qualquer programa de enfermagem; o desenvolvimento dessas qualidades impond€ráveis que devem adornar a personalidade da enfermeira, bem como das características pelas quais o público a identifica, é dever da escola, através do seu corpo docente.

Não existem disciplinas específicas para provocar mudanças de hábitos e atitudes, ou para o desenvolvimento de atitudes profissionais. Mas devem existir as docentes-modelo, capazes de ensinar pelo exemplo, de provocar comportamentos imitativos que levem à adoção de atitudes e hábitos humanos, éticos e profissionais.

Daí a grande responsabilidade das escolas na escolha e seleção dos membros do corpo docente. Essa seleção não pode basear-se apenas na competência e na eficiência profissional de uma candidata, ou na pressa em conseguir mais uma "máquina", para ensinar e orientar os alunos no campo clínico. Devem-se considerar, também, outras características e qualidades, imponderáveis umas, outras suscetíveis de avaliação, ainda que subjetiva. A professora de enfermagem, pelos aspectos específicos desse ensino, tem um contato muito prolongado com os alunos; sua comunicação com eles não se restringe aos diálogos em salas de aula ou nos corredores da escola, como pode ocorrer em outras áreas; processa-se de forma completa durante a prática hospitalar, quando o seu comportamento e toda a sua pessoa se torna alvo da observação cuidadosa e insiste de uma dúzia de olhos ansiosos por uma mensagem qualquer, de aprovação, orientação, incentivo, crítica ou desáprovação, ou ainda, de estímulo para comportamentos que levam os alunos à prestação daqueles cuidados dos quais o doente necessita, da maneira mais rápida e perfeita possível, como a própria professora os dispensaria. 
A docente está sendo constantemente julgada e avaliada; se possuir competência profissional, prestígio e educação social, certamente suas atitudes exercerão influências sobre o comportamento cos alunos, que tenderão a imitá-la, pois essas três qualidades do modelo são as que mais impressionam e sensibilizam os estudantes.

Uma seleção adequada do corpo docente das escolas de enfermagem poderia garantir a preservação dos valores tradicionais da profissão, pela utilização de docentes-modelo que retratassem o tipo de enfermeira que a própria escola pretende preparar para a comunidade; profissionais que realmente agissem de conformidade com o que ensinam e pregam. Enfermeiras que ensinam o dever da assiduidade e da pontualidade, sendo assíduas e pontuais nos seus compromissos, principalmente com os alunos e companheiros de trabalho; que ensinem liderança, exercendo-a em suas atividades na escola, no hospital e na comunidade, que sejam exemplos de simplicidade e elegância no vestir, na linguagem, na comunicação verbal є não verbal com alunos, doentes, pessoal da escola e do hospital; que constituam exemplo de entrosamento e bom relacionamento com todos, profissionais afins, subordinados e pacientes; que não apenas mencionem o interesse e respeito pela pessoa humana, sadia ou doente, com um dos deveres elementares de todo o pessoal da saúde, mas que demonstrem um real interesse pelos problemas daqueles com os quais mantém contato permanente ou esporádico.

O gosto e o entusiasmo pela profissão não surgem espontaneamente. A tendência ou vocação por serviços assistenciais, que leva a jovem candidata a procurar o curso de enfermagem como uma das possibilidades na área da saúde, deve ser alimentada na escola; a displicência, o conformismo, a acomodação e a rotina são o resultado de uma orientação defeituosa, em que o modelo a ser copiado apresenta atitudes negativas em relação às profissões que exerce, de enfermeira e de educadora.

O desinteresse das enfermeiras pela. sua associação de classe vem sendo uma queixa constante do pequeno número de profissionais que se dedicam às atividades sócio-culturais da ABEn. Gosto e entusiasmo pelas programações da entidade de classe também não surgem espontaneamente; devem ser desenvolvidos durante o curso e alimentados pelo exemplo das docentes que, pela participação ativa em movimentos profissionais, culturais e assistenciais, além de cumprirem um dever ético em relação à sua profissão, indicam esse caminho à nova geração.

Valorizar o trabalho em conjunto, objetivando o progresso da profissão e dos profissionais, é uma atitude fácil de desenvolver, se o modelo fôr bom e convincente; o que não é facil é estabelecer critérios para a seleção de docentes que venham a constituir, real- 
mente, exemplos a serem imitados; que possam ensinar pela estratégia da "modelação"; que sejam enfermeiras-modelo e docentesmodelo.

Se alguma recomendação pudesse resultar do presente trabalho, seria no sentido de que as escolas de enfermagem estabelecessem critérios para a seleção de docentes e que o fizessem levando em conta, além da competência profissional, aquelas qualidades que completam a imagem da professoa boa e eficiente: espírito de liderança, habilidade na comunicação e no interrelacionamento pessoal, assiduidade e pontualidade nos compromissos, entusiasmo e gosto pela enfermagem, interesse pelas atividades e pelo progresso da associação de classe; e aquelas qualidades que adornam as personalidades bem formadas, adquiridas através da educação moral, social e estética.

\section{BIBLIOGRAFIA}

KRAMER, Marlene - The concept of modeling as a teaching strateg. Nursing Forum. XI (1): 48-70, 1972.

SHETLAND, Margaret L. - The responsibility of the profissional school for preparing nurses for ethical, moral, and humanistic practicy Nursing Forum, 8 (1) : 17-27, 1969. 